\title{
MARINE PROTECTED AREAS EXEMPLIFY THE EVOLUTION OF SCIENCE AND POLICY
}

By Mark H. Carr, J. Wilson White, Emily Saarman, Jane Lubchenco, Kristen Milligan, and Jennifer E. Caselle

Scuba diver surveying a benthic community (fishes, invertebrates, algae) to evaluate the ecological responses of kelp forest ecosystems to the establishment of marine protected areas in California. Photo credit: Michael Langhans
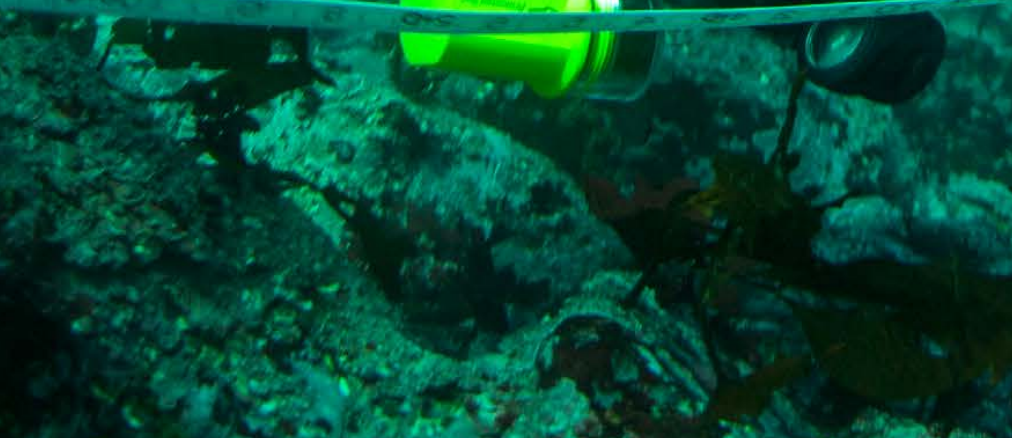
ABSTRACT. The interaction between science and policy is often iterative: policy defines the need for scientific information, and the resulting science shapes future policy. This evolution is exemplified by the history of marine protected areas (MPAs). We describe how some policy applications of MPAs have changed through time from focusing on fisheries to becoming an ecosystem-based conservation tool, and then back to a more integrated fisheries-conservation approach. We show that changing applications of MPAs shaped the kind of research conducted to inform policies and also that the research results influenced those policies (e.g., from fisheries to conservation, and from standalone MPAs to MPA networks). We use California's MPA experience within the California Current Large Marine Ecosystem as a case study to illustrate this process.

\section{INTRODUCTION}

Marine protected areas (MPAs) have become a prominent conservation and management tool in ocean environments around the world. Over the past several decades, the purposes, design, management, and science of MPAs has evolved markedly. From the political science perspective, global efforts to establish MPAs can be classified into three explanatory policy network theories: the "epistemic community," which represents a linear science-driven process; the "advocacy coalition," in which scientists play a role that informs MPA design, along with other stakeholders; and the "discourse coalition," in which scientific information may or may not play a role in structuring the discourse surrounding MPAs (Caveen et al., 2013). Of these policy network theories, the first two provide the clearest path for science to inform MPA establishment and ample opportunities for feedback between policymakers and the scientific community. Here, we provide a chronology of how some MPA purposes (i.e., management applications), and the science that informed their design and evaluation, have evolved through the past three decades, and we mention some of the numerous cases of feedback between them. We draw from a number of reviews that characterize the state of MPA science and policy (Lubchenco et al., 2003; Leslie, 2005; Halpern et al., 2010a). For aspects of the design of MPA networks and for understanding the interplay between science and policy, we draw on our own experience with the Partnership for Interdisciplinary Studies of Coastal Oceans (PISCO) and work of our colleagues in developing the science guidelines for California's network of MPAs (Saarman et al., 2013; Botsford et al., 2014a).

\section{EVOLUTION OF THE MANAGEMENT APPLICATIONS OF MPAS}

A widely accepted definition of MPAs is "a clearly defined geographical space, recognized, dedicated, and managed... to achieve the long-term conservation of nature with associated ecosystem services and cultural values" (IUCN, 2018). However, this has not always been the stated purpose of MPAs, and the applications of MPAs have evolved through time.

One of the earliest records of MPAs is their use by indigenous Pacific peoples of Oceania to manage coastal fisheries for the local sustainability of a common pool resource (Johannes, 1978). Their primary purpose was to maintain local control and stewardship of fishing grounds, and they did not explicitly include the ecosystem- and habitat-based dimensions of modern MPAs. Though these spatial tenure systems declined rapidly following contact with Western civilizations, their success is evidenced by their persistence to the 1980s in island nations (e.g., Palau, Micronesia; Johannes, 1978) as well as a more recent renaissance of traditional community-based management approaches (Friedlander et al., 2013).

\section{MPAs for Fisheries Management}

In the early 1990s, following perceived failures in traditional management, so-called "fishery reserves" were advocated by some fisheries scientists as a tool for enhancing the sustainability of fisheries (e.g., Dugan and Davis, 1993). The mechanisms by which MPAs can increase sustainability include: (1) controlling fishing effort by restricting access to portions of a fished stock, (2) creating spatial buffers against unsuccessful management, (3) reducing impacts to size and age structure, and (4) reducing bycatch. In time, additional potential roles of MPAs would emerge to (5) limit impacts of fisheries on genetic structure, diversity, and selection of life history traits, (6) limit destruction of essential fish habitat, and (7) supplement stock assessments (Claudet, 2011; Baskett and Barnett, 2015).

Protecting the natural age and size structure (3, above) had two objectives. First was protecting the disproportionate contributions of larger female fish to larval production and replenishment of fished populations (Figure 1a). It was also recognized that a fuller size and age distribution of females broadened the ages at which fish spawn, reducing a population's sensitivity to environmental variability (Botsford et al., 2014b). The second objective was the movement of larger individuals from MPAs to adjacent fished areas, increasing the size of fish caught. This so-called "spillover" of larger fish was considered especially relevant for the production of "trophy fish" highly valued in recreational fisheries (Roberts et al., 2001).

\section{MPAs for Ecosystem and \\ Biodiversity Conservation}

As the consequences of MPAs for ecosystem-wide conservation became more apparent and recognition of the ecosystem impacts of fisheries increased, MPAs grew in popularity as an especially effective approach to ecosystem and biodiversity conservation. There was increasing focus on their involvement in (1) maintaining the functional role of harvested species in the ecosystems they inhabit, (2) preventing impacts of fishing on geomorphological and biogenic habitats, and more broadly, (3) protecting the structure and functioning 
of intact ecosystems, including the biodiversity they support. With greater emphasis on ecosystem conservation, regulations extended beyond fishing to prohibiting other anthropogenic impacts (e.g., coastal discharges, aquaculture, mining, energy production structures). Thus, MPAs have become important elements of coastal and marine spatial planning (Halpern et al., 2010a).

\section{MPA Networks for}

Integrated Conservation and

Fisheries Management

The chronology described above shows a dichotomy in the management applications of MPAs between fisheries management and ecosystem-based conservation. While the inextricable linkage between these two goals has long been recognized, the necessity to conceptualize and lever-
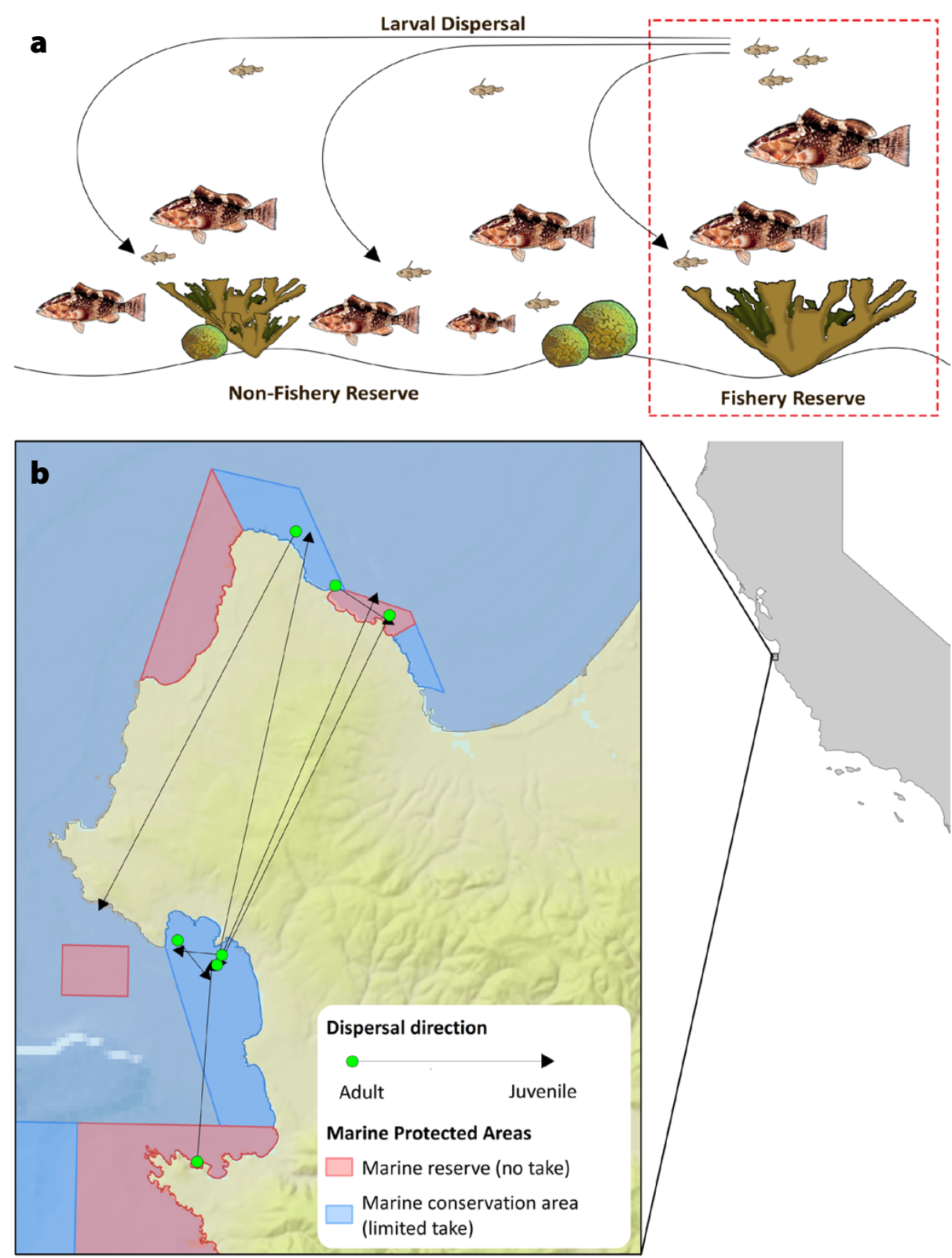

FIGURE 1. (a) Early depiction of the concept of larval "spillover" from a "fishery reserve" to fished populations in a coral reef ecosystem. After Bohnsack (1990) (b) Recent empirical evidence of larval connectivity occurring simultaneously between marine protected areas (MPAs) and from MPAs to fished populations along with self-replenishment within an MPA in central California. After Baetscher et al. (2019) Patterns of connectivity are based on genetic parentage analysis. Lines describe the direction of dispersal from the location of parental origin (filled circle) to recruitment of its offspring (triangle).

age this linkage has become a current focus of MPA policy and science. As networks of MPAs became established, the connections between populations and ecosystems inside and outside of MPAs directed attention toward network-wide, regional management integrated across MPA boundaries, including fisheries and coastal management actions (Gaines et al., 2010). Indeed, in some settings, a well-designed MPA network is critical to an optimal harvest strategy (Rassweiler et al., 2012). Yet, the ecosystem percentages being set aside in MPA networks (typically less than $15 \%-20 \%$ of an ecosystem) emphasize the vulnerability of those networks to mismanaged fisheries outside their boundaries. Additionally, few fisheries management plans and stock assessments accurately account for the status of populations within MPAs (Field et al., 2006).

\section{EVOLUTION OF THE SCIENCE OF MPAS}

The science of MPAs has both influenced the policy application of MPAs and evolved in response to policy needs as MPAs are applied to new management goals. This science includes conceptual and quantitative theory and empirical studies that inform the design of standalone MPAs and MPA networks and evaluate the effectiveness of MPAs at achieving management and conservation goals.

\section{Science of MPAs for Fisheries Management}

The early management emphasis of MPAs as tools to control fishing effort and mortality motivated the development of quantitative models to evaluate the relative consequences of MPAs and more traditional management levers on fisheries yields (Hastings and Botsford, 1999; White et al., 2010a). For the most part, those studies indicated that MPAs could improve fishery yields if a stock is being overharvested. However, if the conventional fishery is well managed, there is a trade-off: increasing MPA area (and thus overall fish biomass) inevitably reduces 
fishery yields, except under certain specific circumstances (Figure 2; White and Kendall, 2007).

Initially, MPAs were designed as standalone areas to enhance the populations of one or a few species. This singlespecies focus generated design criteria based on traits of individual species, including their habitat requirements and movement ranges. The need for data to implement those design criteria launched numerous studies that identified spawning aggregations and mapped critical habitats (e.g., Grüss et al., 2014). The emphasis on enhancing fisheries led to a design trade-off between increasing MPA size to protect more individuals versus ensuring high rates of juvenile and adult spillover to benefit adjacent fisheries. One approach for addressing this trade-off was to develop a design criterion based on the boundary-area ratio; greater boundary lengths relative to MPA area increase spillover. Habitat configuration was also found to influence spillover, with MPAs that partially encompass a reef producing more spillover than MPAs that encompass an isolated reef surrounded by sediment (Tupper, 2007). Simultaneously, empirical studies examined actual rates and distances of spillover (reviewed by Halpern et al., 2010b)

The other mechanism of fishery enhancement-increasing larval production-has been more difficult to study. While fish clearly get larger inside MPAs (Lester et al., 2009) and would have commensurate increases in per capita fecundity (Barneche et al., 2018), quantifying the export of larvae to fished populations is hampered by the difficulty of tracking the movement of planktonic larvae (White et al., 2019, in this issue). With the advent of powerful genetic parentage analysis, several studies have detected MPA self-replenishment, as well as dispersal from MPAs to fished populations and other nearby MPAs (Christie et al., 2010; Harrison et al., 2012; Baetscher et al., 2019; Figure 1b). However, the small number of individual dispersal events detected by these methods leaves much uncertainty about the magnitude of larval export and its effect on regional populations. For now, numerical ocean modeling approaches remain the best way to estimate this type of spillover (e.g., Watson et al., 2010).

One management approach to improving yield included "periodic closures," which were designed to temporarily relieve populations from fishing mortality so they could regenerate and then be opened to fishing again (Game et al., 2009). Rotational closure plans have been successful in boosting yields in some conventional fisheries (e.g., Hart, 2003), are common in tropical Pacific societies (Cohen and Foale, 2013), and may be possible in areas where social constraints make permanent closures unfeasible (Cinner, 2007). However, modeling and empirical studies (e.g., White et al., 2013b) indicate that the rate at which MPAs restore natural size and age structure is much slower than the rate at which they are depleted by fishing. Coupled with the slow recovery of habitats damaged by fishing gear, there appears to be greater value in permanent closures in most cases (but see Goetze et al., 2018). In addition, a growing body of studies demonstrate that strict no-take marine reserves generate stronger population and community-level responses compared to partial-take MPAs (e.g., Edgar et al., 2014).

\section{Ecosystem-Wide Consequences of MPAs and MPA Networks}

Interest in using MPAs for ecosystem and biodiversity conservation has motivated two types of science: empirical assessments of their conservation value, especially community-wide effects, and research aimed at informing design of MPAs for ecosystem and biodiversity conservation (see reviews by Lester et al., 2009; Carr et al., 2018). Many of these studies document how protecting the abundance and functional roles of fished species can have cascading effects on community structures (e.g., Babcock et al., 2010; Caselle et al., 2018). For example, protection of urchin predators (fish and lobsters) inside a California

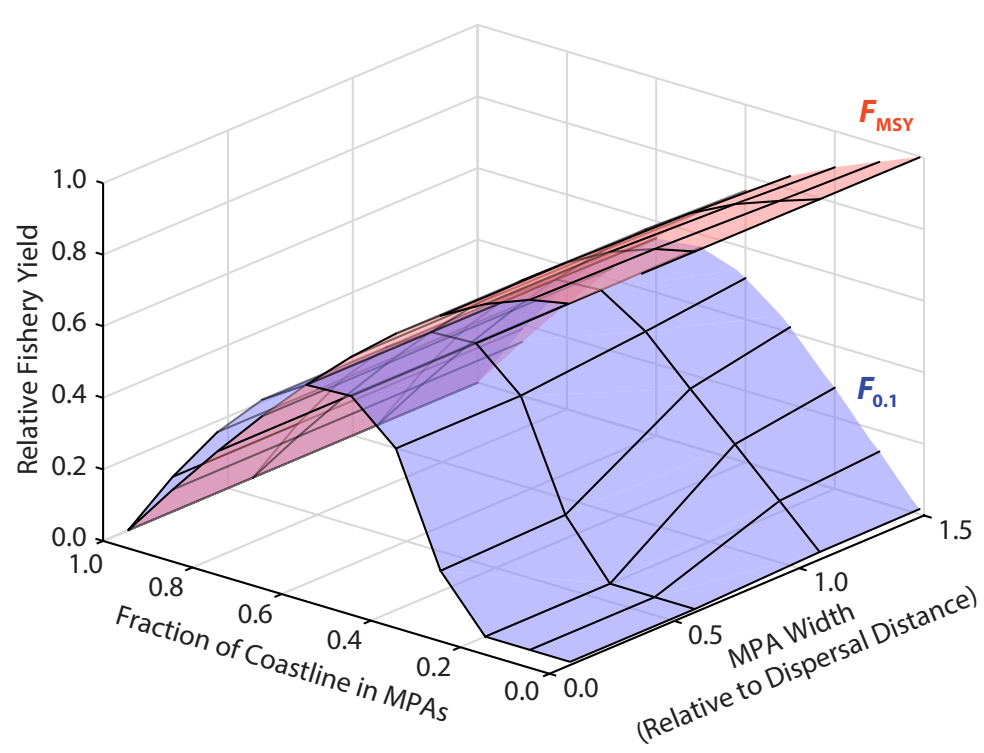

FIGURE 2. Typical results of a spatial population model showing the combined effects of MPA size, fraction of coastline in MPAs, and fishery harvest rate on equilibrium coast-wide fishery yield. This is a model of a generic fish species on a linear coastline, similar to that in Botsford et al. (2001). MPA width is relative to the average larval dispersal distance. The harvest rate in every location is either $F_{\mathrm{MSY}}$, which gives the maximum sustainable yield without MPAs (so yield declines as MPA area increases; red surface), or $F_{0.1}$, which reduces biomass below a sustainable level without MPAs (so yield increases from 0 with either increasing MPA width or total area, but eventually declines as the whole coast is covered; blue surface). 
MPA led to higher density of native kelp and greater resistance to an invasive alga (Caselle et al., 2018). The strength and time for such trophic cascades to manifest and whether they contribute to ecosystem resilience are variable and can be suppressed by consequences of climate change (reviews by Carr et al., 2017, 2018; Bruno et al., 2019).

Another conclusion of this science is that for MPAs to conserve biodiversity, they must represent the diversity of coastal marine ecosystems (Saarman et al., 2013). This type of ecosystem representation is most efficiently achieved either with MPA networks or very large stand-alone MPAs. Moreover, most marine organisms exhibit long-distance larval dispersal and an "open" spatial population structure. This means that populations within most MPAs rely on replenishment by larvae produced elsewhere, which prompted consideration of connected "networks" of MPAs (White et al., 2010b). Additionally, establishing multiple MPAs could protect against catastrophic loss from localized disasters (e.g., hurricanes, oil spills; Allison et al., 2003). Thus, design criteria were needed that accounted for both MPA size and the relationship between larval dispersal distances and the spacing of adjacent MPAs (Gaines et al., 2003). A substantial contribution to this work was generated by an NCEAS (National Center for Ecological Analysis and Synthesis) Working Group on Marine Reserves convened in 1999, which resulted in a special issue of Ecological Applications and several other articles (Lubchenco et al., 2003). In the years since, there has been increasing focus on MPA networks as management tools for entire ecosystems (reviewed by Carr et al., 2017). This trend has been aided by the development of spatial conservation tools that provide MPA design solutions to meet a variety of constraints, including types of ecosystems and total area set aside within MPAs; these tools include Marxan reserve planning software (Ball and Possingham, 2001; Beger et al., 2010) and interactive commu- nity design platforms such as SeaSketch (https://www.seasketch.org).

It was initially thought that explicit patterns of larval connectivity would be the key to designing MPA networks (e.g., Gaines et al., 2003). However, because spatial patterns of dispersal and connectivity differ among species, and tend to be relatively diffuse over large scales, except in cases with highly structured connectivity pathways (e.g. Costello et al., 2010), the focus has shifted to protecting representative habitats, assuming that appropriate MPA spacing will ensure connectivity between adjacent MPAs (Moffitt et al., 2011; Cabral et al., 2016). This leads to the question of how much habitat should be protected inside an MPA, the answer to which also varies among species (Moffitt et al., 2011), though population models can provide some guidance (reviewed by White et al., 2011).

\section{Science of MPA Networks for}

\section{Integrated Conservation and}

\section{Fisheries Management}

The current challenge for management and science is to develop integrated management plans for fisheries and MPAs as well as the scientific tools to inform them. Central to achieving this integration is the development of spatially explicit, coupled population-connectivity models that incorporate spatial and temporal patterns of fishing effort, demographic responses to rates of mortality, and patterns of connectivity and population replenishment based on actual habitat distribution (two examples are described in White et al., 2013a, and Hopf et al., 2016). Such models, informed by empirical estimates of fishing mortality, demography of populations inside and outside MPAs, and oceanographic processes, can be used to evaluate the drivers of regional population and ecosystem performance and predict their dynamics under future oceanographic and management regimes.

Another aspect of this integrated perspective of MPAs and fisheries management that has not yet been fully explored is the application of MPA networks as tools to inform management. Several studies have pointed out how comparing populations inside and outside of MPAs can lead to better interpretation of catch per unit effort and provide stock assessments that compare fished and unfished populations at appropriate spatial and temporal scales (Babcock and MacCall, 2011; McGilliard et al., 2011).

\section{CASE STUDY: IMPACT OF CALIFORNIA'S MLPA ON THE SCIENCE OF MPA NETWORKS}

The establishment of California's MPA network is an example of how policy was influenced by MPA science and science was responsive to the needs of policymakers. In 1999, the California legislature enacted the Marine Life Protection Act (MLPA), directing the design of a statewide MPA network and thus reflecting the conclusions of a recent scientific workgroup (Lubchenco et al., 2003; Gleason et al., 2013). The first two attempts to implement the MLPA failed. The first employed an "epistemic community" approach, in which scientists and agency staff designed an MPA network and only later sought public input. The second, more inclusive "advocacy coalition" approach failed primarily due to inadequate funding (Weible et al., 2004; Fox et al., 2013). The third (successful) attempt shared many characteristics with the second attempt, but was better funded and facilitated. This seven-year planning process enlisted a Science Advisory Team (SAT) tasked with generating design guidelines for the network. The SAT conducted extensive reviews and promoted new research to inform those guidelines (reviewed by Botsford et al., 2014a). Three of six overarching goals of the network identified in the MLPA included (1) protecting the natural structure and functioning of marine ecosystems, (2) restoring and enhancing economically and ecologically significant species, and (3) requiring the system of MPAs to function as an ecological network. Following the literature cited 
above, the SAT defined an ecological network as MPAs that were connected to one another by larval dispersal. The many design criteria that were generated in response to these ecosystem, population, and network goals are briefly summarized here (see also Saarman et al., 2013; White et al., 2013a; Botsford et al., 2014a). Using these guidelines, stakeholder groups created a network of 124 MPAs along the nearly $1,500 \mathrm{~km}$ length of the California coastline (Botsford et al., 2014a).

Two key design criteria identified for ecosystem and biodiversity protection were representation and replication of the many coastal marine ecosystems across a network. Two levels of representation were recognized: first, characterization of ecosystems based on a combination of substrate type (rock vs. soft sediment) and water depth, and second, geographic variation in community composition, or "bioregions," within each of these ecosystems (e.g., Claisse et al., 2018, for southern California). The SAT suggested that MPAs be distributed to encompass these levels of variation in ecosystem structure, and used species-area curves from ecological surveys in each habitat to determine the minimum ecosystem area an MPA would need to encompass to serve as a functional replicate.

Criteria for the minimum size of individual MPAs combined population and ecosystem considerations. The SAT reasoned that at a minimum, an MPA must encompass the home range of individuals to ensure that they can be protected throughout their lifetimes. This prompted an extensive review of fish home ranges (Freiwald, 2012). Additionally, the SAT recognized that many fishes inhabit multiple ecosystems over their lifetimes, such as those that undertake ontogenetic migrations between habitats (e.g., Fodrie and Levin, 2008; Nagelkerken et al., 2012). This led to the recommendation that MPAs encompass multiple ecosystems, from those on beaches to those in deeper shelf waters.

Criteria for the spacing and spatial arrangement of MPAs evolved perhaps most rapidly during the MLPA planning process. At the outset, the SAT recognized that it would be valuable to specify some maximum distance between neighboring MPAs in order to ensure larval connectivity. This was approached by using estimates of "average dispersal distance" based on genetic information, average larval duration, and simplified representations of oceanographic flow (Figure 3; Kinlan and Gaines, 2003; Largier, 2003). Specifying both minimum MPA width and maximum spacing in sequence of indirectly specifying a minimum proportion of the coastline that will be protected, which early spatial population models suggested was a key variable affecting population persistence in MPAs (Botsford et al., 2001). Given those fairly limited point estimates of a single dispersal distance per species, population models were developed to explain how different combinations of dispersal distance and MPA size interacted to the alongshore dimension has the con-

affect population persistence and fishery yield (Kaplan and Botsford, 2005; White et al., 2010a, 2010b). An important lesson that emerged from those analyses was that population dynamics inside MPAs depended heavily on fishery management outside MPAs. By the end of the MLPA process, advances in numerical ocean circulation modeling and the availability of high-resolution benthic habitat maps made it possible to simulate larval connectivity patterns directly. Those connectivity calculations were then used in bioeconomic population dynamics models (White et al., 2013a) to evaluate possible MPA configurations in a way that accounted for spatial variations in dispersal pathways. The bioeconomic models had a side benefit of quantifying the possible economic trade-offs of MPA placement (i.e., lost fishing grounds), though the MLPA itself did not have economic goals.

Like MPAs elsewhere in the world (https://wcmc.io/8408), California's MPAs

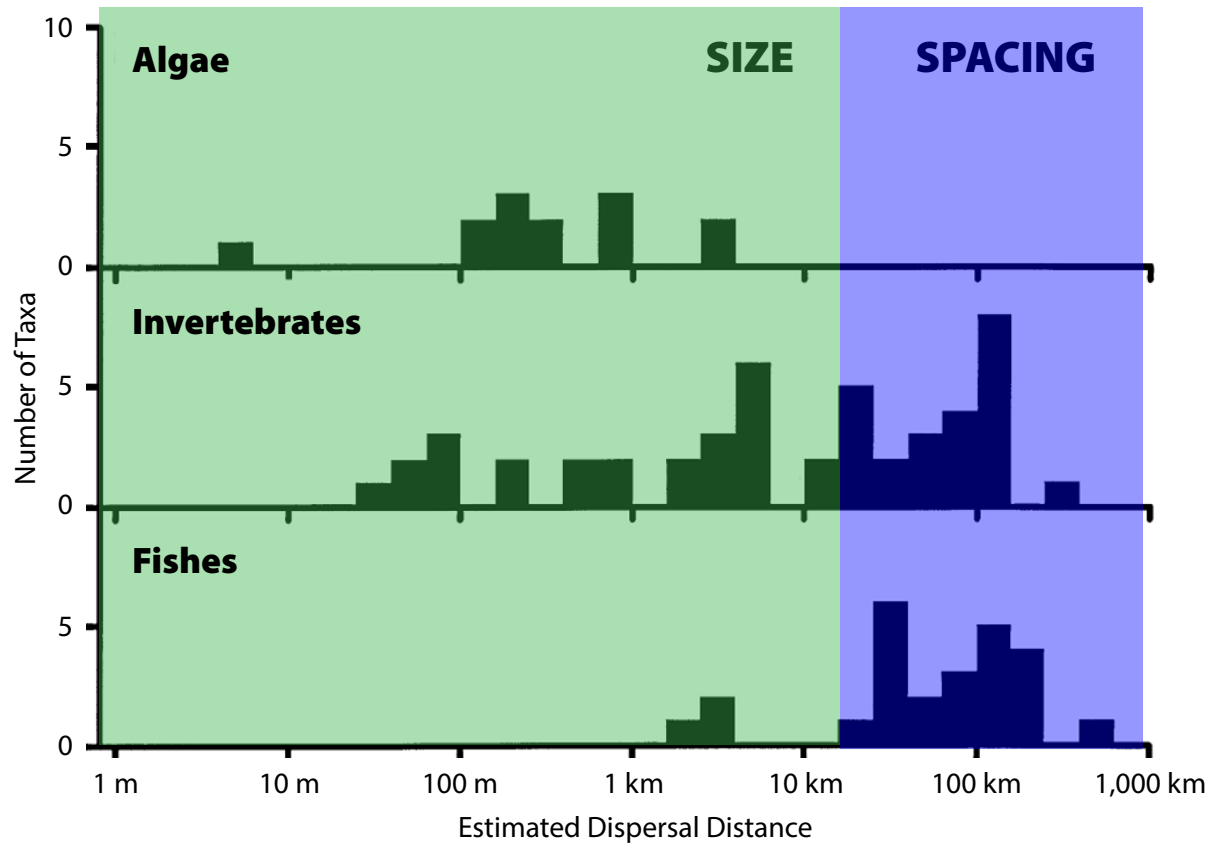

FIGURE 3. Scales of population connectivity relative to California's Marine Life Protection Area (MLPA) size and spacing guidelines and estimates of average propagule (spores or larvae) dispersal distances for more than 100 species. Species with short distance dispersing propagules (e.g., macroalgae, many invertebrates, some fishes) could be self-replenishing in MPAs of 25-100 $\mathrm{km}^{2}$ (green area). Species with long distance dispersing propagules (many invertebrates and fishes) have connectivity among MPAs spaced 50-100 km apart and the fished areas between them. Dispersal estimates are derived from genetic variation among populations using slopes from plots of genetic isolation by distance (Kinlan and Gaines, 2003; Palumbi, 2003; Kinlan et al., 2005). Redrawn from Kinlan and Gaines (2003) 
vary from fully protected (no extractive activities) to highly protected (take restricted to select species) to even lightly protected (broader commercial and recreational fishing allowed). To determine the extent to which partial take MPAs would contribute to ecosystem protections, the SAT devised a novel framework for evaluating the extent to which allowed activities caused deviations in protection from a no-take reserve (Figure 4; Saarman et al., 2013).

\section{FUTURE CHALLENGES AND OPPORTUNITIES FOR MPA SCIENCE AND POLICY}

\section{Climate Change}

Climate change poses both threats and opportunities for the policy applications of MPAs (Carr et al., 2017). The performances of individual MPAs are especially vulnerable to changing environmental conditions associated with climate change (e.g., temperature, oxygen, acidity, currents, nutrient levels; e.g. Bruno et al., 2019), which raises questions for policymakers as to their efficacy for miti- gation and adaptation to climate change. As ocean currents shift, patterns of larval dispersal and connectivity will be altered, potentially jeopardizing the functional integrity of MPA networks (Fox et al., 2016). Conversely, considering MPA networks as management tools to mitigate the consequences of climate change (e.g., Chavez et al., 2017) has spawned new design considerations and empirical assessments of their potential roles (McLeod et al., 2009; Green et al., 2014; Carr et al., 2017). To facilitate the redistribution of species with changing environmental conditions, these considerations include spatial designs that span depth gradients to allow species to shift to refugia in deeper waters, protection of genetic diversity across species ranges, inclusion of habitats that harbor genotypes adapted to tolerate predicted future environmental conditions, and protection of species interactions that resist tropicalization and the influx of non-native species (e.g., Ling and Johnson, 2012; Bates et al., 2014; Caselle et al., 2018). The goal of all of these is to enhance both popu- lation and ecosystem resilience (reviewed by Carr et al., 2017, 2018). Understanding and predicting the possible fisheries and conservation effects of MPAs and MPA networks in response to climate change is one of the greatest challenges to MPA science today.

\section{Evaluation and Adaptive Management}

As the global number of MPAs and networks grows, opportunities to evaluate design and management criteria increase. Evaluation of performance to determine the efficacy of MPAs in meeting management objectives has long been recognized as essential (White et al., 2011; GrorudColvert et al., 2014). There is now a rich literature on the performance evaluations of individual MPAs (many cited above, and Carr et al., 2018), but no evaluations of network performance have been conducted. This is in part because of the paucity of science-based networks, but also because most places in the world lack the capacity (i.e., the network-wide ecological monitoring and connectiv-

\section{Conceptual Model for Determining Levels of Protection}

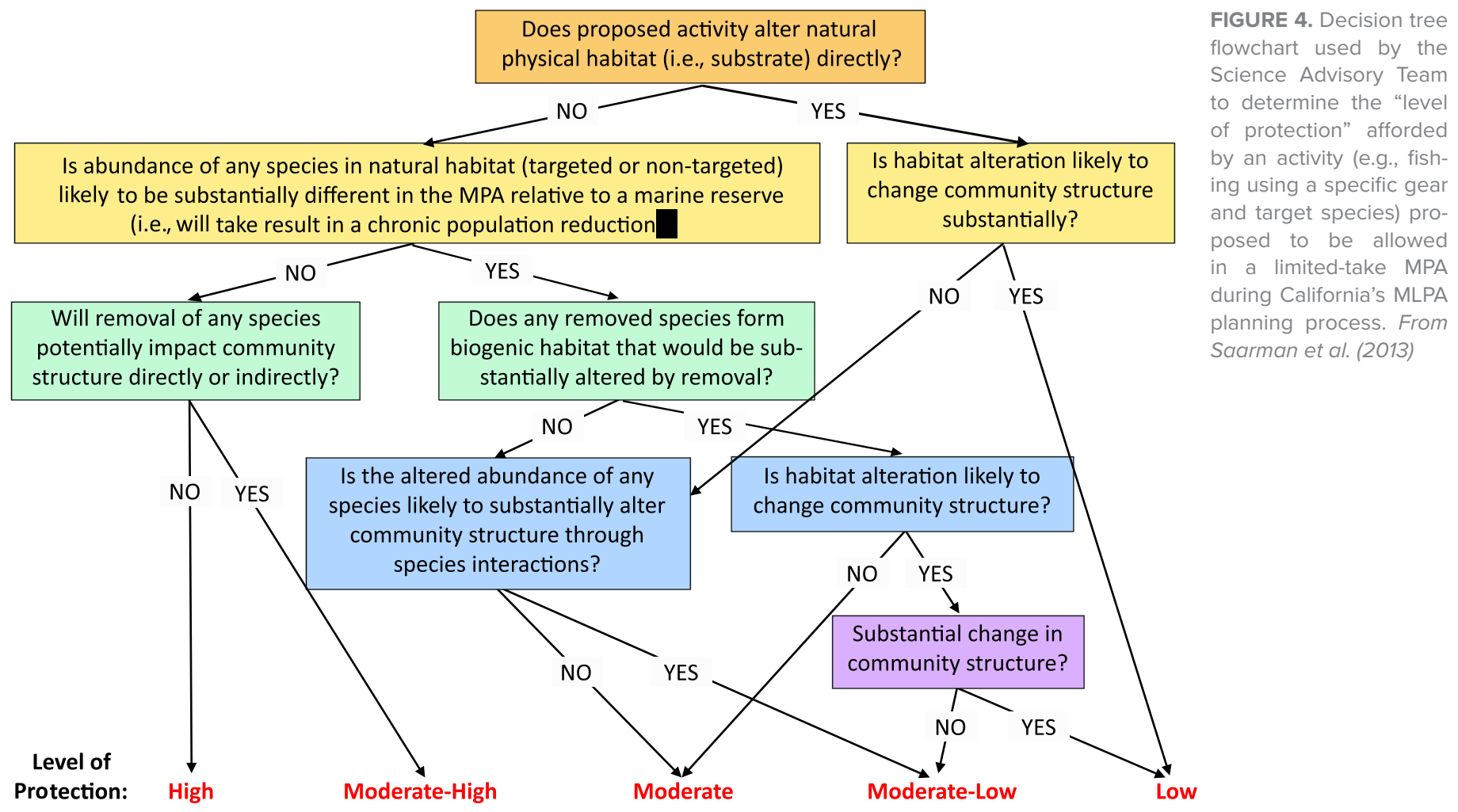


ity modeling) required for full network analyses. Past studies have revealed the prolonged timeframes of population responses (Figure 5; Caselle et al., 2015) and the further delay of community-wide responses (Babcock et al., 2010), as well as the importance of accounting for geographic variation in oceanographic conditions, community structure, and fishing pressure outside MPAs when setting expectations and evaluating performance across a network (Hamilton et al., 2010; Cinner et al., 2018; Nickols et al., in press). Among various evaluation designs proposed (e.g., Grorud-Colvert et al., 2014), the most promising are approaches that combine long-term monitoring studies with the coupled populationconnectivity models described above in the Science of MPA Networks for Integrated Conservation and Fisheries Management section. Such models can manipulate the presence of MPAs to determine both their relative contributions and their dependence on the network and the sizes and fishery yields of region-wide populations. These evaluation programs necessitate interdisciplinary collaborations among empiricists and modelers, ecologists, geneticists, oceanographers, geologists, geographers, and others, and require the application of each discipline's toolset (Young et al., 2017; Addison et al., 2018).

\section{CLOSING REMARKS}

One obvious consequence of using MPAs for both fisheries management and ecosystem and biodiversity conservation is the generation of a wealth of scientific research. That science has been interdisciplinary and has considered fundamental aspects of ecological and evolutionary processes of organisms, populations, communities, and ecosystems. It is also clear that science has continually informed and influenced the applications of MPAs for both fisheries management and conservation. This interplay between science and policy continues to expand the scope of each, especially as we explore the applications of MPAs
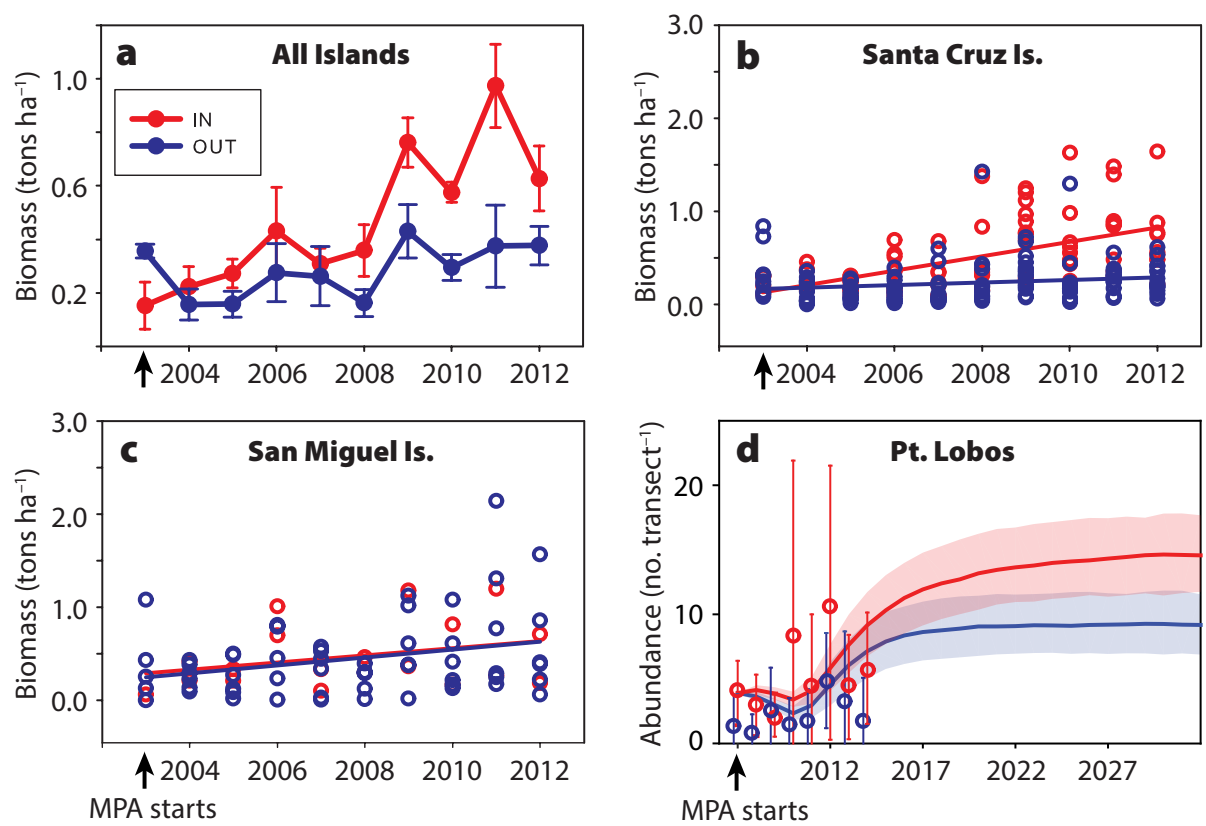

FIGURE 5. Detecting increases in previously fished populations after MPA implementation. (a) Trajectories of biomass of all fishery-targeted species combined at sites inside (red) and outside (blue) of MPAs in the California Channel Islands. At the scale of individual islands, a similar trend is detectable at Santa Cruz Island (b) but not at San Miguel Island (c), due to a combination of recruitment variability and low pre-MPA fishing (each point is one study site). Adapted from Caselle et al. (2015) (d) A population model fit to pre-MPA data at Pt. Lobos, California, predicted that blue rockfish (Sebastes mystinus) abundance would initially drop, then increase (red line and shading indicate mean and $90 \%$ confidence region of trajectories), but it would take $>20$ years for the trend to be distinguishable from the outcome if fishing continued (blue line and shaded region). The model predictions overlapped with visual survey data inside and outside the MPA (red and blue symbols, respectively, with 95\% confidence intervals). Adapted from Nickols et al. (in press)

for ecosystem-based management, for coastal and marine spatial planning, and for adaptation and mitigation of a changing global climate. As broad and influential as this interaction has been, this article has focused solely on the natural sciences and has not considered the critical socioeconomic and biocultural aspects of these social-ecological systems. As we grow to recognize and embrace the importance of these interactions between humans and the marine environment through the lens of MPAs, the scope and benefits of this evolutionary process will only increase. @

\section{REFERENCES}

Addison, P.F.E., D.J. Collins, R. Trebilco, S. Howe, N. Bax, and P. Hedge. 2018. A new wave of marine evidence-based management: Emerging challenges and solutions to transform monitoring, evaluating, and reporting. ICES Journal of Marine Science 75(3):941-952, https://doi.org/10.1093/ icesjms/fs $\times 216$.

Allison, G.W., S.D. Gaines, J. Lubchenco, and H.P. Possingham. 2003. Ensuring persistence of marine reserves: Catastrophes require adopting an insurance factor. Ecological Applications 13:S8-S24, https://doi.org/10.1890/ 1051-0761(2003)013[0008:EPOMRC]2.0.CO;2. Babcock, R.C., N.T. Shears, A.C. Alcala, N.S. Barrett, G.J. Edgar, K.D. Lafferty, T.R. McClanahan, and G.R. Russ. 2010. Decadal trends in marine reserves reveal differential rates of change in direct and indirect effects. Proceedings of the National Academy of Sciences of the United States of America 107(43):18,256-18,261, https://doi.org/ 10.1073/pnas.0908012107.

Babcock, E.A., and A.D. MacCall. 2011. How useful is the ratio of fish density outside versus inside no-take marine reserves as a metric for fishery management control rules? Canadian Journal of Fisheries and Aquatic Sciences 68(2):343-359, https://doi.org/10.1139/F10-146.

Baetscher, D.S., E.C. Anderson, E.A. Gilbert-Horvath, D.P. Malone, E.T. Saarman, M.H. Carr, and J.C. Garza. 2019. Dispersal of a nearshore marine fish connects marine reserves and adjacent fished areas along an open coast. Molecular Ecology 28(7):1,611-1,623, https://doi.org/10.1111/ mec.15044.

Ball, I.R., and H.P. Possingham. 2001. The design of marine protected areas: Adapting terrestrial techniques. Pp. 769-774 in Proceedings of the International Congress on Modelling and Simulation. F. Ghassemi, P. Whetton, R. Little, and M. Littleboy, eds, The Modelling and Simulation Society of Australia and New Zealand Inc. Barneche, D.R., D.R. Robertson, C.R. White, and D.J. Marshall. 2018. Fish reproductive-energy output increases disproportionately with body size. Science 360(6389):642-645, https://doi.org/ 10.1126/science.aao6868. 
Baskett, M.L., and L.A.K.K. Barnett. 2015. The ecological and evolutionary consequences of marine reserves. Annual Review of Ecology, Evolution, and Systematics 46(1):49-73, https://doi.org/10.1146/ annurev-ecolsys-112414-054424.

Bates, A.E., N.S. Barrett, R.D. Stuart-Smith, N.J. Holbrook, P.A. Thompson, and G.J. Edgar. 2014. Resilience and signatures of tropicalization in protected reef fish communities. Nature Climate Change 4(1):62-67, https://doi.org/10.1038/ nclimate2062.

Beger, M., H.S. Grantham, R.L. Pressey, K.A. Wilson, E.L. Peterson, D. Dorfman, P.J. Mumby, R. Lourival, D.R. Brumbaugh, and H.P. Possingham. 2010. Conservation planning for connectivity across marine, freshwater, and terrestrial realms. Biological Conservation 143(3):565-575, https://doi.org/10.1016/j.biocon.2009.11.006.

Bohnsack, J. 1990. The Potential of Marine Fishery Reserves for Reef Fish Management in the US Southern Atlantic. NOAA Technical Memorandum NMFS-SEFC-261, 55 pp, https://doi.org/10.13140/2.1.3007.9369.

Botsford, L.W., A. Hastings, and S.D. Gaines. 2001 Dependence of sustainability on the configuration of marine reserves and larval dispersal distance. Ecology Letters 4:144-150, https://doi.org/10.1046/ j.1461-0248.2001.00208.x.

Botsford, L.W., J.W. White, M.H. Carr, and J.E. Caselle. 2014a. Marine protected area networks in California, USA. Pp. 205-251 in Marine Managed Areas and Fisheries. M.L. Johnson, and J. Sandell, eds, Advances in Marine Biology, vol. 69, https://doi.org/10.1016/ B978-0-12-800214-8.00006-2.

Botsford, L.W., M.D. Holland, J.C. Field, and A. Hastings. 2014b. Cohort resonance: A significant component of fluctuations in recruitment, egg production, and catch of fished populations. ICES Journal of Marine Science 71(8):2,158-2,170, https://doi.org/10.1093/icesjms/fsu063.

Bruno, J.F., I.M. Côté, and L.T. Toth. 2019. Climate change, coral loss, and the curious case of the parrotfish paradigm: Why don't marine protected areas improve reef resilience? Annual Review of Marine Science 11(1):307-334, https://doi.org/ 10.1146/annurev-marine-010318-095300.

Cabral, R.B., S.D. Gaines, M.T. Lim, M.P. Atrigenio, S.S. Mamauag, G.C. Pedemonte, and P.M. Aliño. 2016. Siting marine protected areas based on habitat quality and extent provides the greatest benefit to spatially structured metapopulations. Ecosphere 7(11):e01533, https://doi.org/10.1002/ ecs2.1533.

Carr, M.H., S.P. Robinson, C. Wahle, G. Davis, S. Kroll, S. Murray, E.J. Schumacker, and M. Williams. 2017. The central importance of ecological spatial connectivity to effective coastal marine protected areas and to meeting the challenges of climate change in the marine environment. Aquatic Conservation: Marine and Freshwater Ecosystems 27:6-29, https://doi.org/10.1002/ aqc. 2800

Carr, M.H., K.L.C. Bell, P. Leary, H.L. Sagar, and S. Tucker. 2018. How MPAs Enhance the Resilience of Coastal Marine Ecosystems and Their Services: A Supplemental Report by the Marine Protected Areas Federal Advisory Committee's Ecosystem Team. $24 \mathrm{pp}$

Caselle, J.E., A. Rassweiler, S.L. Hamilton, and R.R. Warner. 2015. Recovery trajectories of kelp forest animals are rapid yet spatially variable across a network of temperate marine protected areas. Scientific Reports 5:1-14, https://doi.org/10.1038/ srep14102.

Caselle, J.E., K. Davis, and L.M. Marks. 2018. Marine management affects the invasion success of a non-native species in a temperate reef system in California, USA. Ecology Letters 21(1):43-53, https://doi.org/10.1111/ele.12869.
Caveen, A.J., T.S. Gray, S.M. Stead, and N.V.C. Polunin. 2013. MPA policy: What lies behind the science? Marine Policy 37(1):3-10, https://doi.org/10.1016/ j.marpol.2012.04.005.

Chavez, F.P., C. Costello, D. Aseltine-Neilson,

H. Doremus, J.C. Field, S.D. Gaines, M. Hall-Arber, N.J. Mantua, B. McCovey, C. Pomeroy, and others (California Ocean Protection Council Science Advisory Team Working Group). 2017. Readying California Fisheries for Climate Change. California Ocean Science Trust, Oakland, CA, 58 pp.

Christie, M.R., B.N. Tissot, M.A. Albins, J.P. Beets, Y. Jia, D.M. Ortiz, S.E. Thompson, and M.A. Hixon. 2010. Larval connectivity in an effective network of marine protected areas. PLOS ONE 5(12):e15715, https://doi.org/10.1371/journal.pone.0015715.

Cinner, J.E. 2007. Designing marine reserves to reflect local socioeconomic conditions: Lessons from long-enduring customary management systems. Coral Reefs 26(4):1,035-1,045, https://doi.org/ 10.1007/s00338-007-0213-2

Cinner, J.E., E. Maire, C. Huchery, M.A. MacNeil, N.A.J. Graham, C. Mora, T.R. McClanahan, M.L. Barnes, J.N. Kittinger, C.C. Hicks, and others. 2018. Gravity of human impacts mediates coral reef conservation gains. Proceedings of the National Academy of Sciences of the United States of America 115(27):E6116-E6125, https://doi.org/ 10.1073/pnas.1708001115.

Claisse, J.T., C.A. Blanchette, J.E. Dugan, J.P. Williams, J. Freiwald, D.J. Pondella, I.I. Nicholas, K.S. David, K. Davis, L.A. Zahn, and others. 2018. Biogeographic patterns of communities across diverse marine ecosystems in southern California. Marine Ecology 39:e12453, https://doi.org/10.1111/ maec.12453.

Claudet, J., ed. 2011. Marine Protected Areas: A Multidisciplinary Approach. Cambridge University Press, Cambridge, UK, 373 pp.

Cohen, P.J., and S.J. Foale. 2013. Sustaining smallscale fisheries with periodically harvested marine reserves. Marine Policy 37(1):278-287, https://doi.org/10.1016/j.marpol.2012.05.010.

Costello, C., A. Rassweiler, D. Siegel, G. De Leo, F. Micheli, and A. Rosenberg. 2010 The value of spatial information in MPA network design. Proceedings of the National Academy of Sciences of the United States of America 107(43):18,294-18,299, https://doi.org/ 10.1073/pnas.0908057107.

Dugan, J.E., and G.E. Davis. 1993. Introduction to the international symposium on marine harvest refugia. Canadian Journal of Fisheries and Aquatic Sciences 50(9):1,991-1,992, https://doi.org/10.1139/ f93-222.

Edgar, G.J., R.D. Stuart-Smith, T.J. Willis, S. Kininmonth, S.C. Baker, S. Banks, N.S. Barrett, M.A. Becerro, A.T.F. Bernard, J. Berkhout, and others. 2014 Global conservation outcomes depend on marine protected areas with five key features. Nature 506(7487):216-220, https://doi.org/10.1038/ nature13022

Field, J.C., A.E. Punt, R.D. Methot, and C.J. Thomson 2006. Does MPA mean 'Major Problem for Assessments'? Considering the consequences of place-based management systems. Fish and Fisheries 7:284-302, https://doi.org/10.1111/ .1467-2979.2006.00226.x.

Fodrie, F.J., and L.A. Levin. 2008. Linking juvenile habitat utilization to population dynamics of California halibut. Limnology and Oceanography 53(2):799-812, https://doi.org/ 10.4319/lo.2008.53.2.0799.

Fox, E., M. Miller-Henson, J. Ugoretz, M. Weber, M. Gleason, J. Kirlin, M. Caldwell, and S. Mastrup 2013. Enabling conditions to support marine protected area network planning: California's Marine Life Protection Act Initiative as a case study. Ocean \& Coastal Management 74:14-23, https://doi.org/ 10.1016/j.ocecoaman.2012.07.005.
Fox, A.D., L. Henry, D.W. Corne, and J.M. Roberts. 2016. Sensitivity of marine protected area network connectivity to atmospheric variability. Royal Society Open Science 3:160494, https://doi.org/ 10.1098/rsos.160494.

Freiwald, J. 2012. Movement of adult temperate reef fishes off the west coast of North America. Canadian Journal of Fisheries and Aquatic Sciences 69(8):1,362-1,374, https://doi.org/10.1139/ f2012-068.

Friedlander, A.M., J.M. Shackeroff, and J.N. Kittinger. 2013. Customary marine resource knowledge and use in contemporary Hawai'i. Pacific Science 67(3):441-460, https://doi.org/10.2984/ 67.3.10.

Gaines, S.D., B. Gaylord, and J.L. Largier. 2003. Avoiding current oversights in marine reserve design. Ecological Applications 13(sp1):32-46, https://doi.org/10.1890/1051-0761(2003)013[0032: ACOIMR]2.0.CO;2

Gaines, S.D., C. White, M.H. Carr, and S.R. Palumbi. 2010. Designing marine reserve networks for both conservation and fisheries management. Proceedings of the National Academy of Sciences of the United States of America 107(43):18,286-18,293, https://doi.org/ 10.1073/pnas.0906473107.

Game, E.T., M. Bode, E. McDonald-Madden, H.S. Grantham, and H.P. Possingham. 2009. Dynamic marine protected areas can improve the resilience of coral reef systems. Ecology Letters 12(12):1,336-1,345, https://doi.org/ 10.1111/j.1461-0248.2009.01384.x.

Gleason, M., J. Kirlin, and E. Fox. 2013. California's marine protected area network planning process: Introduction to the special issue. Ocean \& Coastal Management 74:1-2, https://doi.org/10.1016/ j.ocecoaman.2012.08.022.

Goetze, J.S., J. Claudet, F. Januchowski-Hartley, T.J. Langlois, S.K. Wilson, C. White, R. Weeks, and S.D. Jupiter. 2018. Demonstrating multiple benefits from periodically harvested fisheries closures. Journal of Applied Ecology 55:1,102-1,113, https://doi.org/10.1111/1365-2664.13047.

Green, A.L., L. Fernandes, G. Almany, R. Abesamis, E. McLeod, P.M. Aliño, A.T. White, R. Salm, J. Tanzer, and R.L. Pressey. 2014. Designing marine reserves for fisheries management, biodiversity conservation, and climate change adaptation. Coasta Management 42(2):143-159, https://doi.org/10.1080/ 08920753.2014 .877763

Grorud-Colvert, K., J. Claudet, B.N. Tissot, J.E. Caselle, M.H. Carr, J.C. Day, A.M. Friedlander, S.E. Lester, T. Lison de Loma, D. Malone, and others. 2014. Marine protected area networks: Assessing whether the whole is greater than the sum of its parts. PLOS ONE 9(8):e102298, https://doi.org/ 10.1371/journal.pone.0102298.

Grüss, A., J. Robinson, S.S. Heppell, S.A. Hellell, and B.X. Semmens. 2014. Conservation and fisheries effects of spawning aggregation marine protected areas: What we know, where we should go, and what we need to get there. ICES Journal of Marine Science 71(7):1,515-1,534, https://doi.org/10.1093/ icesjms/fsu038.

Halpern, B.S., S.E. Lester, and K.L. McLeod. 2010a. Placing marine protected areas onto the ecosys tem-based management seascape. Proceedings of the National Academy of Sciences of the United States of America 107(43):18,312-18,317, https://doi.org/10.1073/pnas.0908503107.

Halpern, B.S., S.E. Lester, and J.B. Kellner. 2010b. Spillover from marine reserves and the replenishment of fished stocks. Environmental Conservation 36(4):268-276, https://doi.org/ 10.1017/S0376892910000032.

Hamilton, S.L., J.E. Caselle, D.P. Malone, and M.H. Carr. 2010. Incorporating biogeography into evaluations of the Channel Islands marine reserve network. Proceedings of the National Academy of Sciences of the United States of America 107(43):1,822-1,827, https://doi.org/ 10.1073/pnas.0908091107. 
Harrison, H.B., D.H. Williamson, R.D. Evans, G.R. Almany, S.R. Thorrold, G.R. Russ, K.A. Feldheim, L. van Herwerden, S. Planes, M. Srinivasan, and others. 2012. Larval export from marine reserves and the recruitment benefit for fish and fisheries. Current Biology 22(11):1,023-1,028, https://doi.org/10.1016/j.cub.2012.04.008.

Hart, D.R. 2003. Yield- and biomass-per-recruit analysis for rotational fisheries, with an application to the Atlantic sea scallop (Placopecten magellanicus). Fishery Bulletin 101(1):44-57.

Hastings, A., and L.W. Botsford. 1999. Equivalence in yield from marine reserves and traditional fisheries management. Science 284:1,537-1,538, https://doi.org/10.1126/science.284.5419.1537.

Hopf, J.K., G.P. Jones, D.H. Williamson, and S.R. Connolly. 2016. Fishery consequences of marine reserves: Short-term pain for longer-term gain. Ecological Applications 26(3):818-829, https://doi.org/10.1890/15-0348.

IUCN (International Union for Conservation of Nature). 2018. Applying IUCN's Global Conservation Standards to Marine Protected Areas (MPAs). Gland, Switzerland, 4 pp.

Johannes, R.E. 1978. Traditional marine conservation methods in Oceania and their demise. Annual Review of Ecology and Systematics 9:349-364, https://doi.org/10.1146/ annurev.es.09.110178.002025.

Kaplan, D.M., and L.W. Botsford. 2005. Effects of variability in spacing of coastal marine reserves on fisheries yield and sustainability. Canadian Journal of Fisheries and Aquatic Sciences 62:905-912, https://doi.org/10.1139/f04-243.

Kinlan, B.P., and S.D. Gaines. 2003. Propagule dispersal in marine and terrestrial environments: A community perspective. Ecology 84(8):2,007-2,020, https://doi.org/10.1890/01-0622.

Kinlan, B.P., S.D. Gaines, and S.E. Lester. 2005. Propagule dispersal and the scales of marine community process. Diversity and Distributions 11(2):139-148, https://doi.org/10.1111/ j.1366-9516.2005.00158.x.

Largier, J.L. 2003. Considerations in estimating larval dispersal distance from oceanographic data. Ecological Applications 13(sp1):71-89, https://doi.org/10.1890/1051-0761(2003)013[0071: CIELDDI2.0.CO;2.

Leslie, H.M. 2005. A synthesis of marine conservation planning approaches. Conservation Biology 19(6):1,701-1,713, https://doi.org/10.1111/ j.1523-1739.2005.00268.x.

Lester, S.S.E., B.B.S. Halpern, K. Grorud-Colvert, J. Lubchenco, B.I.B. Ruttenberg, S.D.S. Gaines, S. Airamé, and R.R.R. Warner. 2009. Biological effects within no-take marine reserves: A global synthesis. Marine Ecology Progress Series 384:33-46, https://doi.org/10.3354/ meps08029.

Ling, S.D., and C.R. Johnson. 2012. Marine reserves reduce risk of climate-driven phase shift by reinstating size-and habitat-specific trophic interactions. Ecological Applications 22(4):1,232-1,245, https://doi.org/10.1890/11-1587.1.

Lubchenco, J., S.R. Palumbi, S.D. Gaines, and S. Andelman. 2003. Plugging a hole in the ocean: The emerging science of marine reserves. Ecological Applications 13(sp1):3-7, https://doi.org/10.1890/1051-0761(2003)013[0003: PAHITO]2.0.CO;2.

McGilliard, C.R., R. Hilborn, A. MacCall, A.E. Punt, and J.C. Field. 2011. Can we use information from marine protected areas to inform management of small-scale, data-poor stocks? ICES Journal of Marine Science 68(1):201-211, https://doi.org/ 10.1093/icesjms/fsq151.

McLeod, E., R. Salm, A. Green, and J. Almany. 2009. Designing marine protected area networks to address the impacts of climate change. Frontiers in Ecology and the Environment 7(7):362-370, https://doi.org/10.1890/070211.
Moffitt, E.A., J. W. White, and L.W. Botsford. 2011. The utility and limitations of size and spacing guidelines for designing marine protected area (MPA) networks. Biological Conservation 144(1):306-318, https://doi.org/10.1016/j.biocon.2010.09.008.

Nagelkerken, I., M.G.G. Grol, and P.J. Mumby. 2012. Effects of marine reserves versus nursery habitat availability on structure of reef fish communities. PLOS ONE 7(6):e36906, https://doi.org/10.1371/ journal.pone.0036906.

Nickols, K.J., J.W. White, D.P. Malone, M.H. Carr, R.M. Starr, M.L. Baskett, A. Hastings, and L.W. Botsford. In press. Setting ecological expectations for adaptive management of marine protected areas. Journal of Applied Ecology, https://doi.org/ 10.1111/1365-2664.13463.

Palumbi, S.R. 2003. Population genetics, demographic connectivity and the design of marine reserves. Ecological Applications 13(sp1):146-158, https://doi.org/10.1890/1051-0761(2003)013[0146: PGDCAT]2.0.CO;2.

Rassweiler, A., C. Costello, and D.A. Siegel. 2012. Marine protected areas and the value of spatially optimized fishery management. Proceedings of the National Academy of Sciences of the United States of America 109(29):11,884-11,889, https://doi.org/ 10.1073/pnas.1116193109.

Roberts, C.M., J.A. Bohnsack, F. Gell, J.P. Hawkins, and R. Goodridge. 2001. Effects of marine reserves on adjacent fisheries. Science 294(5548):1,920-1,923, https://doi.org/ 10.1126/science. 294.5548.1920.

Saarman, E.T., M. Gleason, J. Ugoretz, S. Airamé, M.H. Carr, E. Fox, A. Frimodig, T. Mason, and J. Vasques. 2013. The role of science in supporting marine protected area network planning and design in California. Ocean \& Coastal Management 74:45-56, https://doi.org/10.1016/ j.ocecoaman.2012.08.021.

Tupper, M.H. 2007. Spillover of commercially valuable reef fishes from marine protected areas in Guam, Micronesia. Fishery Bulletin 105(5):527-537, https://www.worldfishcenter.org/content/spillovercommercially-valuable-reef-fishes-marineprotected-areas-guam-micronesia.

Watson, J.R., S. Mitarai, D.A. Siegel, J.E. Caselle, C. Dong, and J.C. McWilliams. 2010. Realized and potential larval connectivity in the southern California bight. Marine Ecology Progress Series 401:31-48, https://doi.org/10.3354/ meps08376.

Weible, C., P.A. Sabatier, and M. Lubell. 2004. A comparison of a collaborative and top-down approach to the use of science in policy: Establishing marine protected areas in California. Policy Studies Journal 32(2):187-208, https://doi.org/10.1111 j.1541-0072.2004.00060.x.

White, C., and B.E. Kendall. 2007. A reassessment of equivalence in yield from marine reserves and traditional fisheries management. Oikos 116:2,039-2,043, https://doi.org/10.1111/ j.2007.0030-1299.16167.x.

White, J.W., L.W. Botsford, E.A. Moffitt, and D.T. Fischer. 2010a. Decision analysis for designing marine protected areas for multiple species with uncertain fishery status. Ecological Applications 20(6):1,523-1,541, https://doi.org/ 10.1890/09-0962.1.

White, J.W., L.W. Botsford, A. Hastings, and J.L. Largier. 2010b. Population persistence in marine reserve networks: Incorporating spatial heterogeneities in larval dispersal. Marine Ecology Progress Series 398:49-67, https://doi.org/10.3354/ meps08327.

White, J.W., L.W. Botsford, M.L. Baskett, L.A.K. Barnett, R.J. Barr, and A. Hastings. 2011. Linking models with monitoring data for assessing performance of no-take marine reserves. Frontiers in Ecology and the Environment 9(7):390-399, https://doi.org/ 10.1890/100138.

White, J.W., A.J. Scholz, A. Rassweiler, C. Steinback, L.W. Botsford, S. Kruse, C. Costello, S. Mitarai, D.A. Siegel, P.T. Drake, and others. 2013a.
A comparison of approaches used for economic analysis in marine protected area network planning in California. Ocean \& Coastal Management 74:77-89, https://doi.org/10.1016/ j.ocecoaman.2012.06.006.

White, J.W., L.W. Botsford, A. Hastings, M.L. Baskett, D.M. Kaplan, and L.A.K. Barnett. 2013b. Transient responses of fished populations to marine reserve establishment. Conservation Letters 6(3):180-191, https://doi.org/10.1111/j.1755-263X.2012.00295.x.

White, J.W., M.H. Carr, J.E. Caselle, L. Washburn, C.B. Woodson, S.R. Palumbi, P.M. Carlson, R.R. Warner, B.A. Menge, J.A. Barth, and others. 2019. Connectivity, dispersal, and recruitment: Connecting benthic communities and the coastal ocean. Oceanography 32(3):50-59, https://doi.org/ 10.5670/oceanog.2019.310.

Young, M.A., L.W. Wedding, and M.H. Carr. 2017. Applying landscape ecology to evaluate the design of marine protected area networks. Pp. 429-452 in Seascape Ecology: Taking Landscape Ecology into the Sea. S. Pittman, ed., John Wiley \& Sons, Chichester, UK.

\section{ACKNOWLEDGMENTS}

The manuscript benefited greatly by comments from the editor and three external reviewers. This work was supported by the David and Lucile Packard Foundation. This is contribution 495 from PISCO, the Partnership for Interdisciplinary Studies of Coastal Oceans.

\section{AUTHORS}

Mark H. Carr (mhcarr@ucsc.edu) is Professor, Department of Ecology and Evolutionary Biology, University of California, Santa Cruz, CA, USA J. Wilson White is Assistant Professor, Coastal Oregon Marine Experiment Station, Oregon State University, Newport, OR, USA. Emily Saarman is Associate Specialist, Department of Ecology and Evolutionary Biology, University of California, Santa Cruz, CA, USA. Jane Lubchenco is University Distinguished Professor, Department of Integrative Biology, Oregon State University, Corvallis, OR, USA. Kristen Milligan is Assistant Professor Senior Research, Department of Integrative Biology, Oregon State University, Corvallis, OR, USA. Jennifer E. Caselle is Research Biologist, Marine Science Institute, University of California, Santa Barbara, CA, USA

\section{ARTICLE CITATION}

Carr, M.H., J.W. White, E. Saarman, J. Lubchenco, K. Milligan, and J.E. Caselle. 2019. Marine protected areas exemplify the evolution of science and policy. Oceanography 32(3):94-103, https://doi.org/10.5670/ oceanog.2019.315.

\section{COPYRIGHT \& USAGE}

This is an open access article made available under the terms of the Creative Commons Attribution 4.0 International License (https://creativecommons.org/ licenses/by/4.0/), which permits use, sharing, adaptation, distribution, and reproduction in any medium or format as long as users cite the materials appropriately, provide a link to the Creative Commons license, and indicate the changes that were made to the original content. 